\title{
Bimetal-organic framework-derived carbon nanocubes with 3D hierarchical pores as highly efficient oxygen reduction reaction electrocatalysts for microbial fuel cells
}

\author{
Neng Chen ${ }^{1,2}$, Zihan Meng ${ }^{1,2}$, Rui Wang ${ }^{2}$, Shichang Cai ${ }^{2}$, Weibin Guo ${ }^{2}$ and Haolin Tang ${ }^{1,2^{*}}$
}

\begin{abstract}
Noble metal-free and highly efficient electrocatalytic materials with hierarchically porous structures continue to be studied for the oxygen reduction reaction (ORR) in microbial fuel cells (MFCs). We report bimetal-organic framework (bi-MOF)-derived nanocubic Swiss cheese-like carbons with a novel three-dimensional hierarchically porous structure (3D Co-N-C) prepared by utilizing cetyltrimethylammonium bromide (CTAB) as a structure-directing agent to control the formation of a nanocubic skeleton, and silica spheres as a template to form a mesoporous structure. The elemental composition and chemical morphology of this material can be tuned through the $\mathrm{Zn} / \mathrm{Co}$ ratio to optimize its ORR catalytic activity. The optimized 3D Co-N-C displays excellent ORR catalytic performance (half-wave potential as high as $0.754 \mathrm{~V}$ vs. reversible hydrogen electrode and diffusion-limiting current density of $5.576 \mathrm{~mA} \mathrm{~cm}^{-2}$ ) in $0.01 \mathrm{~mol} \mathrm{~L}^{-1}$ phosphate-buffered saline (PBS electrolyte), showing it can compete with the commercial $20 \mathrm{wt} \% \mathrm{Pt} / \mathrm{C}$ catalysts. The catalytic capability and long-term durability of 3D Co-N-C as an air-filled cathode electrocatalyst in an MFC device are tested, showing that the 3D CoNC-MFC can reach a high power density of $1257 \mathrm{~mW} \mathrm{~m}^{-2}$ and provide a competitive voltage during a periodic feeding operation for $192 \mathrm{~h}$; these values are much higher than those of the Pt/C-MFC.
\end{abstract}

Keywords: Co-N-doped carbon, structure-oriented approach, 3D hierarchically porous nanocubes, oxygen reduction reaction, microbial fuel cells

\section{INTRODUCTION}

Microbial fuel cells (MFCs), as a new type of electrochemical energy conversion system, are widely praised as an up-and-coming candidate for replacing traditional fossil energy and have promising application prospects in energy recovery from factory wastewater, biomass energy, and marine sediment [1-4]. In particular, MFCs use active bacteria that decompose carbohydrates as the anode electrode to release electrons, while the oxygen on the cathode is reduced by electrons to generate electricity [5-7]. At present, the oxygen reduction reaction (ORR) performance on the MFC cathode has become the main limiting factor in the further improvement of this technology due to its high overpotential and slow reaction kinetics. Platinum $(\mathrm{Pt})$-based electrocatalysts have long been counted as the most suitable catalysts for the ORR. Nonetheless, the poor durability, high cost, and scarce reserves of Pt resources have become obstacles to the amplification and commercialization of MFCs [8,9], thereby promoting a surge of research on inexpensive nonnoble metal catalysts with comparable activity and long-term durability.

Transition metal- and nitrogen-doped carbon (Me-NC) materials, as a promising electrocatalyst for the ORR, have been widely investigated as prospective substitutes for Pt-free electrocatalysts on account of their relatively low price, superior electrocatalytic performance, environmental friendliness, and distinguished durability $[10,11]$. Moreover, this research field has undergone considerable foundational work, which has been widely

${ }^{1}$ Foshan Xianhu Laboratory of the Advanced Energy Science and Technology Guangdong Laboratory, Xianhu Hydrogen Valley, Foshan 528200, China

${ }^{2}$ State Key Laboratory of Advanced Technology for Materials Synthesis and Processing, Wuhan University of Technology, Wuhan 430070, China * Corresponding author (email: thln@whut.edu.cn) 
recognized [12-18]. Metal-organic frameworks (MOFs), as a novel type of porous crystal material assembled by the coordination bond self-assembly of inorganic metal ions/clusters and organic ligands, are universally taken as precursors of Me-N-C electrocatalysts [19,20]. These derivatives show excellent catalytic performance with regard to ORR catalytic activity because they have various structures with a high specific surface area, a stable microcellular structure, and the unique properties of functional groups on the ligands to expose more active area. However, current research on the Me-N-C of MOF derivatives is hindered, and the reasons are summarized [21-24] as follows. (i) The lack of precise control of the composition and structure of the catalyst leads to uneven numbers of active sites, insufficient exposure, and microstructural agglomeration, which often limits the effective mass and electron transfer [25]. (ii) Most of the Me-N-C materials derived from MOFs possess a lower density than Pt-based precious metal materials, increasing the occupied volume and the thickness of the electrode film; this structure affects the enrichment and diffusion of specific gas molecules and effectively hinders mass transfer. (iii) It is necessary to simultaneously explore and optimize these materials in different harsh environments, such as in acidic, neutral, and alkaline electrolytes. Therefore, there is an urgent need to explore a new type of porous carbon, in which the elemental composition and structure can be precisely adjusted, while also being able to be widely used under various harsh conditions [26-30].

The inspiration of science often comes from life. Based on attention to food in daily life, some cheeses possess a loose and porous shape, which inspired us to consider making MOF-derived materials with porous structures that look like Swiss cheese. Herein, we report an MOFderived Swiss cheese-like carbon with a novel three-dimensional hierarchically porous nanocubic framework (3D Co-N-C) by the self-adjusted thermal decomposition of $\mathrm{Co} / \mathrm{Zn}$ bi-MOFs, in which cetyltrimethylammonium bromide (CTAB) acts as a structure-orienting surfactant to control the formation of a cubic skeleton, and silica spheres act as a template to form a hierarchically porous structure. 3D Co-N-C possesses unique structural advantages of an interconnected network of hierarchical pores, a high specific surface area, excellent electronic conduction, and evenly dispersed $\mathrm{Co} / \mathrm{N} / \mathrm{C}$ species [31-35]. Hierarchically porous materials can not only provide multidimensional electron transport pathways, shorter diffusion paths, and transport channels, but also provide an abundance of active sites for catalyzing the
ORR. The above structure and characteristics exhibit superb ORR catalytic performance, long-term durability, and methanol resistance, making 3D Co-N-C competitive with commercial $20 \mathrm{wt} \% \mathrm{Pt} / \mathrm{C}$ catalysts in alkaline, neutral, and acidic electrolytes. Moreover, these novel catalysts are assembled into an air-filled cathode of an MFC apparatus (CoNC-MFC) as a diffusion electrode, and the high performance of the MFC device is verified with a maximum output power density up to $1257 \mathrm{~mW} \mathrm{~m}^{-2}$. Furthermore, the CoNC-MFC has excellent durability and can stably run for more than $192 \mathrm{~h}$.

\section{EXPERIMENTAL SECTION}

\section{Synthesis of the $\mathrm{Zn}(100-x) \operatorname{Cox}(\mathrm{MeIM}) @ \mathrm{SiO}_{2}$ nanocubes} Nitrogen-doped carbons with 3D hierarchically porous nanocubes were prepared by hard template casting and structure-oriented self-assembly. In general, $30 \mathrm{mg}$ of $\mathrm{CTAB}$ was dispersed in $60 \mathrm{~mL}$ of aqueous solution containing $6 \mathrm{mmol}$ of $\mathrm{Zn}\left(\mathrm{NO}_{3}\right)_{2} \cdot 6 \mathrm{H}_{2} \mathrm{O}, \mathrm{Co}\left(\mathrm{NO}_{3}\right)_{2} \cdot 6 \mathrm{H}_{2} \mathrm{O}$ or a mixture of both with stirring to obtain a homogeneous colloidal solution. This solution was subsequently mixed with $210 \mathrm{~mL}$ of aqueous solution containing $27.24 \mathrm{~g}$ of 2methylimidazole (MeIM) and $0.5 \mathrm{~g}$ of silicon dioxide $\left(\mathrm{SiO}_{2}\right)$ nanospheres (particle size of approximately $15 \mathrm{~nm}$ ) by vigorous stirring for $30 \mathrm{~min}$. This homogeneous colloidal mixture was separated by centrifugation, washed thoroughly at least six times and fully dried for $12 \mathrm{~h}$ at $80^{\circ} \mathrm{C}$ to obtain $\mathrm{Zn}(100-x) \operatorname{Co} x(\mathrm{MeIM}) @ \mathrm{SiO}_{2}$, wherein $x(x$ $=0,5,10,20,50,100)$ represents the molar fraction of Co ions. For comparison purposes, a powder sample was prepared with a similar synthesis process and composition, except that $\mathrm{SiO}_{2}$ nanospheres were not included; this sample was denoted as Zn90Co10(MeIM).

\section{Synthesis of the Mes-C-N-Zn(100-x)Cox and Mic-C-N- \\ Zn90Co10 Swiss cheese-like nanocubes}

The powders of the prepared structures dominated by mesoporous nanocubes (Mes-C-N-Zn(100-x)Cox (MeIM)) and micropore nanocubes (Mic-Zn90Co10 (MeIM)) were annealed at $850^{\circ} \mathrm{C}$ for $2 \mathrm{~h}$ at a heating speed of $5^{\circ} \mathrm{C} \min ^{-1}$ in a $\mathrm{N}_{2}$-filled atmosphere, and the product was further etched with a $10 \mathrm{wt} \%$ solution of hydrofluoric acid (HF) for $3 \mathrm{~h}$ to eliminate the nanosilica template and yield 3D Mes-Co-N-C porous electrocatalysts. All of the above-obtained products were denoted as Mes-C-N-Zn(100-x)Cox, while the sample without the $\mathrm{SiO}_{2}$ template was labeled Mic-C-NZn90Co10 as a reference substance. 


\section{Characterization of materials}

X-ray diffraction (XRD, BRUKER AXS GMBH, D8 Advance) measurements were recorded on a D/MAX-RB Xray diffractometer by using a $\mathrm{Cu} \mathrm{Ka}$ radiation source. The microstructure of the prepared materials was characterized by scanning electron microscopy (SEM, Zeiss Ultra Plus), transmission electron microscopy (TEM, JEOL JEM-2100F), and energy dispersive spectroscopy (EDS, JEM 2100F). The valence state and content of each element were characterized by X-ray photoelectron spectroscopy (XPS, VG Multilab 2000X-spectrometer PHI 5000 Versa Probe ULVAC). The $\mathrm{N}_{2}$ adsorption-desorption isotherms were subjected to a vacuum at $150^{\circ} \mathrm{C}$ for $10 \mathrm{~h}$ in a nitrogen atmosphere using a Micromeritics Tristar II 3020 analyzer to calculate the specific surface area and pore size distribution.

\section{Electrochemical ORR measurements}

The electrochemical tests were accomplished by a CHI $660 \mathrm{E}$ electrochemical workstation with a standard threeelectrode system consisting of an ORR catalyst-loaded rotating disc electrode (RDE), platinum substrate, and reversible hydrogen electrode. Before adequately manufacturing the working electrode, the ink containing the electrocatalyst, composed of the catalyst sample $(5.0 \mathrm{mg})$, deionized water $(100 \mu \mathrm{L})$, a $5 \mathrm{wt} \% \mathrm{Nafion}^{\circledR}$ solution $(20 \mu \mathrm{L})$, and isopropanol $(900 \mu \mathrm{L})$, was ultrasonically treated for at least $30 \mathrm{~min}$, dropwise added on a glassy carbon electrode (loading of $0.5 \mathrm{mg} \mathrm{cm}^{-2}$ ) and dried naturally. Linear sweep voltammetry (LSV) experiments were accomplished in the potential range of $0.2-1.2 \mathrm{~V}$ at a sweep speed of $10 \mathrm{mV} \mathrm{s}^{-1}$; additionally, different speeds were used in $0.01 \mathrm{~mol} \mathrm{~L}^{-1} \mathrm{~N}_{2} / \mathrm{O}_{2}$-saturated phosphatebuffered saline (PBS) electrolyte ( $\mathrm{pH} 7.0), 0.1 \mathrm{~mol} \mathrm{~L}^{-1}$ $\mathrm{HClO}_{4}$, and $0.1 \mathrm{~mol} \mathrm{~L}^{-1} \mathrm{KOH}$. The long-term durability was obtained by appraising the amperage current $v s$. time (i-t method) curve at a voltage of $0.6 \mathrm{~V}$. The durability of the sample toward methanol was also tested by the $i-t$ method, except that $3 \mathrm{~mol}$ of methanol was added at the appropriate time point (400 s).

The electron transfer number $(n)$ can be calculated by the Koutecky-Levich (K-L) equation:

$$
\begin{aligned}
& 1 / j=1 / j_{\mathrm{L}}+1 / j_{\mathrm{k}}=1 /\left(B \omega^{1 / 2}\right)+1 / j_{\mathrm{k}}, \\
& B=0.62 n F C_{0}\left(D_{0}\right)^{2 / 3} v^{-1 / 6},
\end{aligned}
$$

where $j, j_{\mathrm{k}}$, and $j_{\mathrm{L}}$ represent the measured current density and the kinetic- and diffusion-limiting current densities, respectively; $\omega$ and $n$ represent the rotational speed and electron transfer number, respectively; $F$ represents the
Faraday constant $\left(96,485 \mathrm{C} \mathrm{mol}^{-1}\right) ; C_{0}$ is the bulk concentration of oxygen $\left(1.2 \times 10^{-6} \mathrm{~mol} \mathrm{~cm}^{-3}\right) ; D_{0}$ is the diffusion coefficient of oxygen in $0.01 \mathrm{~mol} \mathrm{~L}^{-1}$ PBS electrolyte $\left(1.9 \times 10^{-5} \mathrm{~cm}^{2} \mathrm{~s}^{-1}\right)$; and $v$ stands for the kinematic viscosity of the electrolyte $\left(0.01 \mathrm{~cm}^{2} \mathrm{~s}^{-1}\right)$.

\section{MFC test}

The application of the 3D Co-N-C nanocubes in MFCs is an indicator of their potential industrialization. Taking a $\mathrm{Pt} / \mathrm{C}-\mathrm{MFC}$ as a contrast, the electrocatalytic performance of 3D hierarchically porous $\mathrm{Co}-\mathrm{N}-\mathrm{C}$ in an MFC (3D CoNC-MFC) was examined with an air-filled cathode. In this case, the carbon cloth purchased from Fuel Cell Earth (AvCarb 1071 HCB) was used as the anode, while the air cathode was carbon paper (area of $16 \mathrm{~cm}^{2}$ ) loaded with the catalyst $\left(0.5 \mathrm{mg} \mathrm{cm}^{-2}\right)$. The $3 \mathrm{D} \mathrm{Co}-\mathrm{N}-\mathrm{C}$ nanocube catalyst or Pt/C catalyst was added to $100 \mu \mathrm{L}$ of isopropanol and $7 \mu \mathrm{L} \mathrm{mg}^{-1} 15 \% \mathrm{Nafion}^{\circledR}$ from DuPont to make a catalyst slurry that was subsequently dropwise added onto the air cathode. After the synthesized air cathode was dried for $24 \mathrm{~h}$, a membrane electrode was formed by hot pressing on the surface of the proton exchange membrane. Regarding the MFC test experiments, $1 \mathrm{~mL}$ of mature Escherichia coli $\mathrm{K}-12$ strain was injected into $10 \mathrm{~mL}$ of anolyte $\left(0.01 \mathrm{~mol} \mathrm{~L}^{-1} \mathrm{PBS}, 5 \times 10^{-3} \mathrm{~mol} \mathrm{~L}^{-1}\right.$ 2-hydroxy-1,4-naphthoquinone (HNQ), $5 \mathrm{~g} \mathrm{~L}^{-1}$ glucose, and $5 \mathrm{~g} \mathrm{~L}^{-1}$ yeast extract). HNQ was chosen as the mediator mainly because it has a high Coulomb output and can boost the electron shuttle transport [36,37]. The battery voltage $v s$. time $(V-t)$ curve of the MFCs was recorded by a voltage collector (Agilent, 34901A), in which the external load resistance was $1000 \Omega$. After the membrane electrode was immersed for at least $6 \mathrm{~h}$ to stabilize it, the polarization curve and power output of the MFC were tested. The MFC durability tests were performed separately for $192 \mathrm{~h}$.

\section{RESULTS AND DISCUSSION}

Nanocubic Co-Zn-N-C electrocatalysts with 3D hierarchically porous structures were synthesized by hard template casting and structure-oriented self-assembly combined with annealing in a nitrogen atmosphere, as shown in Fig. 1a. First, $\mathrm{Zn} x \mathrm{Co}(100-x)(\mathrm{MeIM}) @ \mathrm{SiO}_{2}$ was generated by a coordination reaction with cobalt and zinc nitrate as the coordination metal source, MeIM as the carbon source, CTAB as the surfactant and $\mathrm{SiO}_{2}$ microspheres as templates under water system conditions. Next, the Co-Zn-N-C@SiO ${ }_{2}$ carbon material was formed by annealing $\mathrm{Zn} x \mathrm{Co}(100-x)(\mathrm{MeIM}) @ \mathrm{SiO}_{2}$ at $850^{\circ} \mathrm{C}$ for $2 \mathrm{~h}$ in a $\mathrm{N}_{2}$-filled atmosphere. 

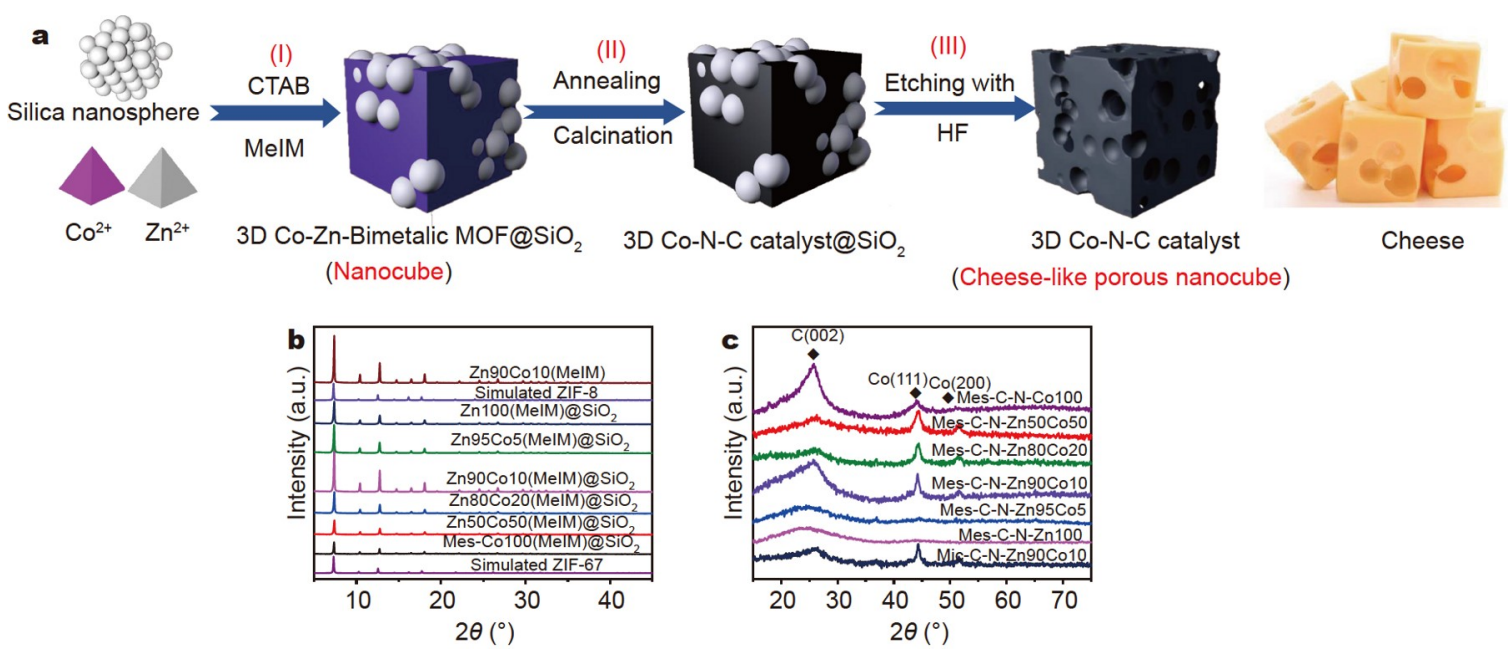

(Cheese-like porous nanocube)

Figure 1 (a) Diagram showing the synthesis of the 3D hierarchically porous Co-N-C skeleton; (b) XRD patterns of $\mathrm{Zn}(100-x) \operatorname{Co} x\left(\mathrm{MeIM} @ \mathrm{SiO}_{2}(x\right.$ $=0,5,10,20,50,100)$, Zn90Co10(MeIM), simulated ZIF-8 and ZIF-67; (c) XRD patterns of Mes-C-N-Zn $(100-x) \operatorname{Cox}(x=0,5,10,20,50,100)$ and Mic-C-N-Zn90Co10.

Finally, hierarchically porous Co-Zn-N-C nanocubic Swiss cheese-like carbon was fabricated through etching with $10 \mathrm{wt} \% \mathrm{HF}$ solution. The macrophysical picture of the bi-MOF with a content of $100 \%$ zinc is milky white, while the color of the powder turns light blue with the addition of Co (Fig. S1). With an increasing Co content, the blue color becomes obvious, which preliminarily indicates the successful synthesis of bi-MOF. This synthesis method has the following advantages: (1) the synthesis of the cubic MOF of this material is carried out at room temperature instead of under high-temperature and highpressure hydrothermal synthesis conditions. In addition, the reaction time is short, and the operation is very simple, which is suitable for large-scale mass production. (2) Compared with the toxic, flammable and explosive methanol used in the traditional preparation of ZIF-8, we use environmentally friendly, safe, and inexpensive deionized water as the solvent. The crystal structure of carbonized $\mathrm{Zn}(100-x) \operatorname{Co} x$ (MeIM) (bi-MOF) was confirmed by XRD, revealing that the typical crystal structure matches well with that of ZIF-8 and ZIF-67 (Fig. 1b). It is worth noting that the peak of the crystal structure becomes increasingly sharper as the $\mathrm{Zn}$ content increases. The crystal peak of $\mathrm{Zn90Co10(MeIM)@SiO} 2$ is the sharpest, which illustrates its higher crystallinity and provides favorable conditions for the catalytic reaction. After hightemperature carbonization, these seven samples show diffraction peaks at $26^{\circ}$, corresponding to the carbon (002) diffraction peak in the catalyst material. When 5\% cobalt nitrate and $95 \%$ zinc nitrate are used, the XRD pattern only shows the diffraction peak of the above carbon, indicating that when the proportion of cobalt nitrate used in the preparation process is small, no metal particles are present or the content is too low to detect. As the proportion of cobalt nitrate is increased to $10 \%$, Search Match software shows that the diffraction peak of Co (PDF No. 15-0806) appears in the XRD pattern, indicating that Co exists in the form of metallic Co in Mes$\mathrm{C}-\mathrm{N}-\mathrm{Zn} 90 \mathrm{Co} 10$. As the proportion of cobalt nitrate continues to increase, the prepared samples also have diffraction peaks of metallic Co. In addition, Mic-C-N-

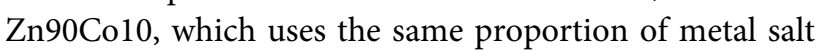
without the introduction of $\mathrm{SiO}_{2}$, is similar to Mes-C-N-

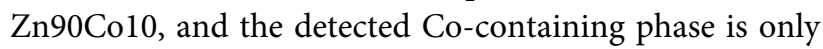
metallic Co (Fig. 1c).

The as-obtained Mic-Zn90Co10(MeIM) and Mic-C-NZn90Co10 were visualized by using SEM and TEM. The SEM images recorded at high magnification clearly show that Mic-Zn90Co10(MeIM) and Mic-C-N-Zn90Co10 consist of well-defined nanocubic shapes with sizes of approximately $100 \mathrm{~nm}$ and are characterized by uniform shapes and flat surfaces, as illustrated in Fig. $2 \mathrm{a}-\mathrm{d}$. The above results are completely different from the structure of the ZIF-8/ZIF-67 dodecahedron in previous studies $[38,39]$. In this reaction system, CTAB not only acts as a surfactant but also an encapsulant. The surface energy and adhesion energy of the long hydrophobic hydrocarbon chain of CTAB interacts differently with the various crystal planes of ZIF-8 crystals. For instance, comparing the (110) and (111) crystal faces, CTAB mo- 

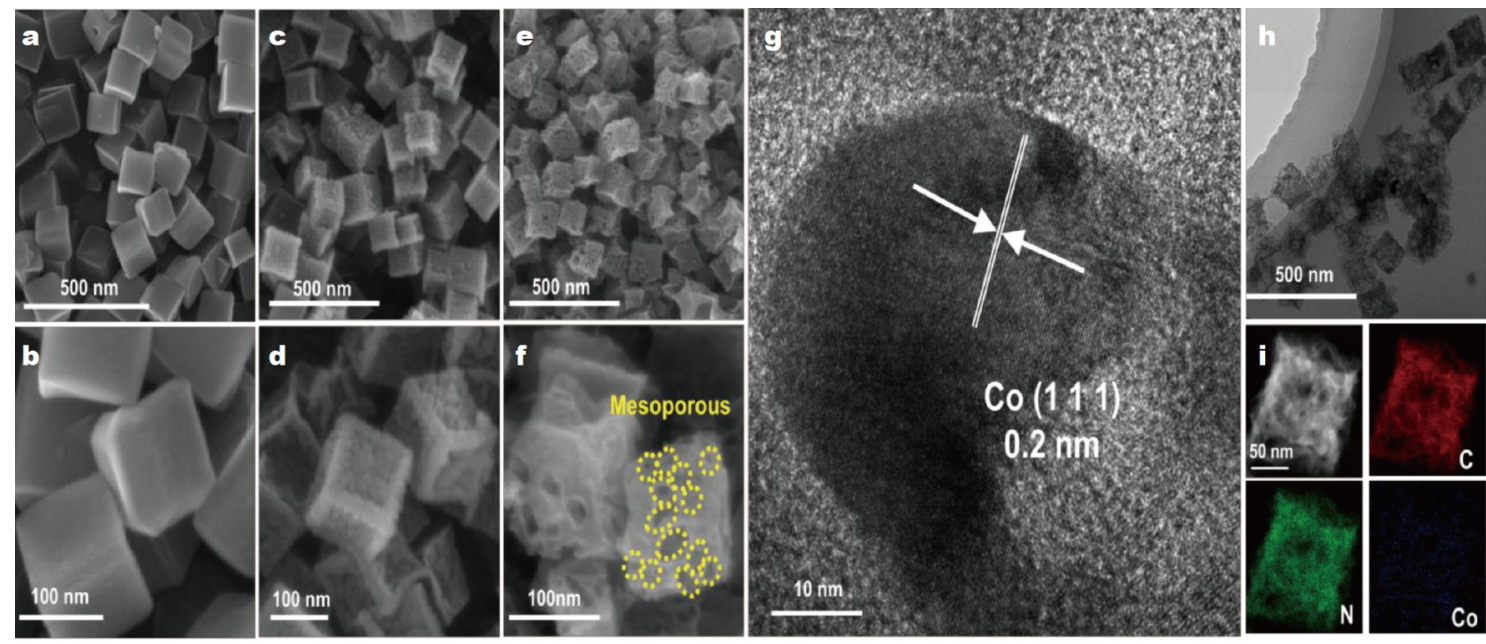

Figure 2 Physical characterizations. SEM images: (a, b) Mic-Zn90Co10(MeIM) nanocubes, (c, d) Mic-C-N-Zn90Co10 nanocubes and (e, f) Mes-CN-Zn90Co10 nanocubes. TEM images: (g) HRTEM and (h) TEM images of the Mes-C-N-Zn90Co10 nanocubes. (i) Elemental mapping of the Mes-C$\mathrm{N}-\mathrm{Zn} 90 \mathrm{Co} 10$ nanocubes.

lecules are more inclined to adsorb on the (100) crystal face, thereby suppressing the growth rate of the (100) crystal face; thus, the morphology and particle size of the ZIF crystal change from a rhombic dodecahedron to a cube $[40,41]$. This theory was also verified by the Material Studio $\odot$ morphology software package simulation calculation. Furthermore, the cube-structured material created by CTAB has also been widely confirmed and applied $[42,43]$. The Mes-C-N-Zn90Co10 prepared by the nanocasting method using silica nanospheres as hard templates has a nanocubic structure with a highly porous structure and a pore size of $15 \mathrm{~nm}$, as shown in Fig. 2e, f. The high-resolution picture indicates that the lattice fringes of the Co nanoparticles embedded in the facecentered cubic lattice (111) are $0.20 \mathrm{~nm}$ (Fig. 2g). As presented in Fig. 2h, Mes-C-N-Zn90Co10 displays a porous nanocubic structure. The highly dispersed state of $\mathrm{C}, \mathrm{N}$, and $\mathrm{Co}$ on the nanocube was confirmed by the corresponding elemental mapping in Fig. 2i [44].

To further explore and verify the microscopic hierarchical porosity of the prepared materials formed by $\mathrm{SiO}_{2}$ as a hard template, the properties of the ZIF-derived carbon were evaluated by nitrogen adsorption/desorption isotherms. The porous Mes-C-N-Zn(100-x)Cox nanocubic catalysts show the type-IV isothermal characteristics of mesoporous materials (Fig. 3a). Mes-C-N-Zn(100 $-x)$ Cox exhibits a greater adsorption in the region of $P / P_{0}$ $>0.4$ with a visible hysteresis curve, demonstrating the presence of mesopores [45]. The surface area of the MesC-N-Zn $(100-x) \operatorname{Cox}$ nanocubes decreases significantly from 1123.92 to $493.56 \mathrm{~m}^{2} \mathrm{~g}^{-1}$ with increasing Co content because of the fusion of cobalt species to severe clusters of graphene during carbonization; additionally, as the proportion of zinc decreases, the number of micropores produced by volatilization decreases (Table S1). The evaporation of $\mathrm{Zn}$ atoms in the MOF produces a large number of micropores during annealing pyrolysis, so an increase in the content of $\mathrm{Zn}$ contributes to expanding the specific surface area and providing more catalytically active sites, which are beneficial for the catalytic reaction. The pore diameter distribution of all samples, which is calculated by the Barrett-Joyner-Halenda (BJH) method, indicates that Mes-C-N-Zn $(100-x) \mathrm{Co} x$ has hierarchical micropores-mesopores, while Mic-C-N-Zn90Co10 has an abundance of only micropores in Fig. $3 \mathrm{~b}$, which is consistent with the TEM images.

The elemental composition of the near-surface region and the bond energy state in Mes-C-N-Co100, Mes-C-NZn90Co10, and Mes-C-N-Zn100 were measured by XPS (Fig. 4). Fig. 4a shows the XPS survey spectra of Mes-C$\mathrm{N}-\mathrm{Zn} 100$, Mes-C-N-Co100, and Mes-C-N-Co100, which contain obvious $\mathrm{C} 1 \mathrm{~s}, \mathrm{~N} 1 \mathrm{~s}$, and $\mathrm{O} 1 \mathrm{~s}$ peaks. Fig. $4 \mathrm{~b}$ shows that Mes-C-N-Zn100 exhibits obvious Zn 2p characteristic peaks, while Mes-C-N-Zn90Co10 has no obvious $\mathrm{Zn}$ $2 p$ characteristic peaks. The elemental analysis in Table S2 shows that the $\mathrm{Zn}$ content of Mes-C-NZn90Co10 is only $0.28 \%$, indicating that the addition of Co lowers the boiling point of $\mathrm{Zn}$ and promotes its volatilization. The N 1s XPS spectrum of the three samples show three obvious characteristic peaks with the chemical 

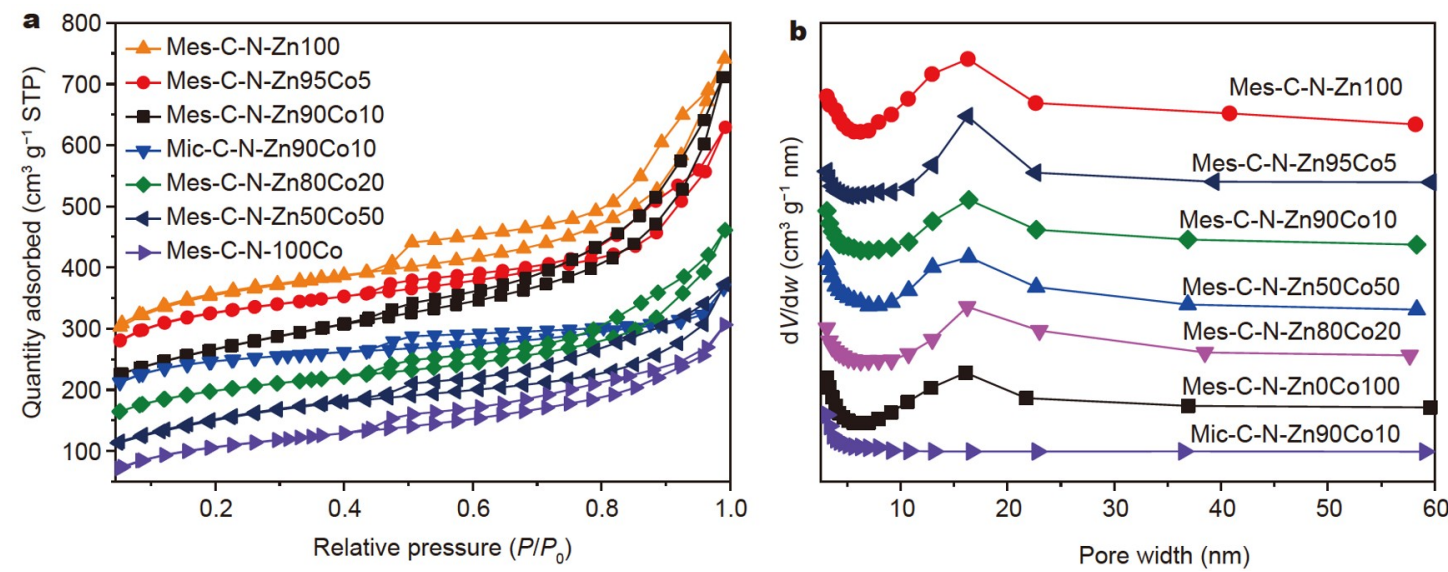

Figure 3 (a) $\mathrm{N}_{2}$ adsorption/desorption isotherms and (b) corresponding pore size distributions of Mes-C-N-Zn(100-x)Cox and Mic-C-NZn90Co10.
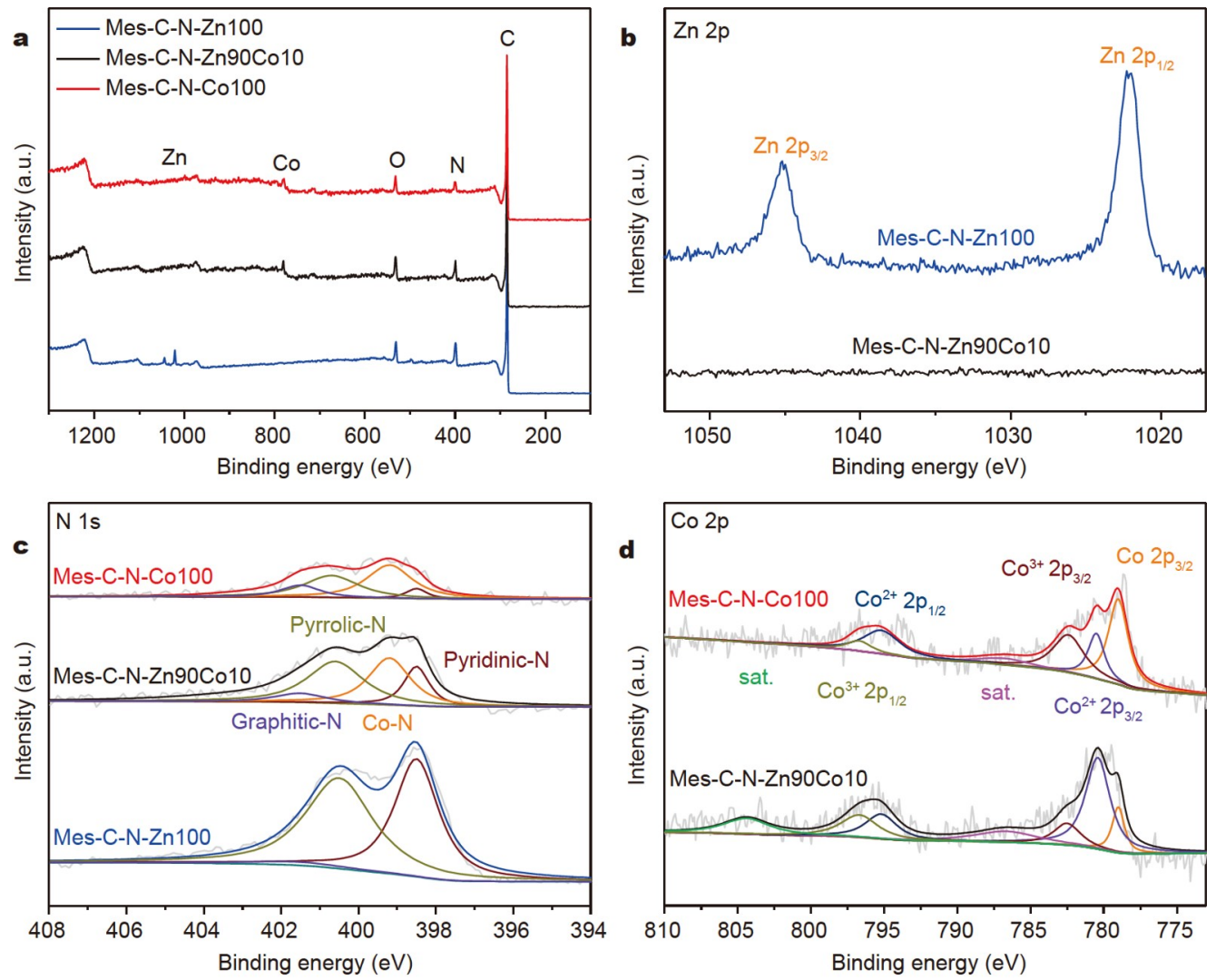

Figure 4 XPS survey spectra of the (a) full spectrum; (b) Zn 2p; (c) N 1s; and (d) Co 2p of the Mes-C-N-Zn100, Mes-C-N-Zn90Co10, and Mes-C-NCo100 catalysts.

binding energies of graphitic-N $(401.1 \pm 0.3 \mathrm{eV})$, pyrrolic$\mathrm{N}(400.5 \pm 0.3 \mathrm{eV})$, and pyridinic-N $(398.5 \pm 0.2 \mathrm{eV})[46]$ (Fig. $4 \mathrm{c}$ and Table S3); these peaks demonstrate that there are more active sites that are condusive to charge transfer [47]. As the $\mathrm{Co} / \mathrm{Zn}$ ratio increases, the $\mathrm{N}$ content of the material decreases, and thus the intensity of the $\mathrm{N} 1 \mathrm{~s}$ peak decreases. In addition, we find the presence of $\mathrm{Co}-\mathrm{N}$ in Mes-C-N-Zn90Co10 and Mes-C-N-Co100, and the coordination sites of the $\mathrm{Co}$ and $\mathrm{N}$ in the materials act as the electrocatalytic active sites for the ORR. Fig. 4 d shows the Co 2p peaks of Mes-C-N-Zn90Co10 and Mes-C-NCo100, confirming that Mes-C-N-Co100 has a large 
proportion of zero-valent $\mathrm{Co}(778.5 \mathrm{eV})$, which is consistent with the Co metal present in the XRD results, while Mes-C-N-Zn10Co90 has a low Co peak because excess Co particles do not chemically coordinate with C, $\mathrm{N}$ or $\mathrm{O}$, thereby existing independently in Mes-C-NCo100. In addition, based on the analysis of the Co $2 p$ spectrum of Mes-C-N-Zn90Co10 and the elemental mapping by TEM, the oxidation states of $\mathrm{Co}$ and $\mathrm{N}$ inside the Mes-C-N-Zn90Co10 material form a ligand and are evenly distributed throughout the carbon material. Coupled with the well-developed hierarchically porous structure, the catalytic active sites can be fully used in the catalytic reaction, which is beneficial to improving the catalytic activity and stability of the material [48].

In this work, the working electrodes, formed by coating Mes-C-N-Zn $(100-x)$ Co $x$ and Mic-C-N-Zn90Co10 on an $\mathrm{RDE}$, were immersed in oxygen-saturated $0.01 \mathrm{~mol} \mathrm{~L}^{-1}$ PBS electrolyte (pH 7.0), $0.1 \mathrm{~mol} \mathrm{~L}^{-1} \quad \mathrm{HClO}_{4}$, and $0.1 \mathrm{~mol} \mathrm{~L}^{-1} \mathrm{KOH}$, respectively, to appraise the electrocatalytic activity based on the half-wave potentials (labeled $E_{1 / 2}$ ) and limiting current densities (labeled $J$ ) at $0.2 \mathrm{~V} v s$. RHE of the RDE polarization curves. In particular, the LSV tests of Mes-C-N-ZnxCo100- $x$, Mic-C-N$\mathrm{Zn} 90 \mathrm{Co} 10$ and $\mathrm{Pt} / \mathrm{C}$ were correspondingly scanned from high to low voltages.

It is quite clear that Mes-C-N-Zn90Co10, which presents superior ORR catalytic activity $\left(E_{1 / 2}\right.$ of $0.754 \mathrm{~V}$, and $J$ of $5.576 \mathrm{~mA} \mathrm{~cm}^{-2}$ at $\left.1600 \mathrm{r} \mathrm{min}^{-1}\right)$, is more remarkable than Mic-C-N-Zn90Co10 ( $E_{1 / 2}$ of $0.745 \mathrm{~V}$, and $J$ of $\left.4.705 \mathrm{~mA} \mathrm{~cm}^{-2}\right)$ and $\mathrm{Pt} / \mathrm{C}\left(E_{1 / 2}\right.$ of $0.746 \mathrm{~V}, J$ of $5.336 \mathrm{~mA} \mathrm{~cm}^{-2}$ ) in $0.01 \mathrm{~mol} \mathrm{~L}^{-1}$ PBS electrolyte ( $\mathrm{pH} \mathrm{7.0)}$ (Fig. 5a). This result is mainly because compared with Mic-C-N-Zn90Co10, Mes-C-N-Zn90Co10 not only contains a large number of exposed micropores but also possesses a large number of mesopores that promote the mass transfer of oxygen, which is conducive to an increase in the limiting current and promotes the catalysis process. Additionally, Mes-C-N-Zn90Co10 exhibits the best catalytic activity among other carbon-based electrocatalysts with different $\mathrm{Co} / \mathrm{Zn}$ ratios (Fig. 5d). Furthermore, LSV was performed at speeds of 400, 800, 1200, 1600 , and $2000 \mathrm{r} \mathrm{min}^{-1}$ to explore the catalytic performance of the different electrocatalysts (Fig. S2). A highly porous structure is conducive to oxygen transfer, which promotes the performance of the catalyst with regard to the limiting current and potential.

The K-L graph and number of electrons transferred per $\mathrm{O}_{2}$ molecule $(n)$ were determined and fitted from the LSV curves to more deeply explore the catalytic mechanism of the ORR. The K-L plots of Mes-C-N-Zn $(100-x)$ Cox show good linearity with analogous parallel fitting lines and first-order reaction kinetics from 0.2 to $0.5 \mathrm{~V}$. The electron transfer number of Mes-C-N-Zn90Co10 $(n=3.95)$ is larger than that of Mic-C-N-Zn90Co10 ( $n=3.89)$, showing that the ORR process by Mes-C-N-Zn90Co10 approaches a 4-electron pathway. The calculated Tafel slope of Mes-C-N-Zn90Co10 $\left(65.01 \mathrm{mV} \mathrm{dec}^{-1}\right)$ is smaller than that of $\mathrm{Pt} / \mathrm{C}\left(65.69 \mathrm{mV} \mathrm{dec}^{-1}\right)$, and the prepared Mic-C-N-Zn90Co10 MOF-derived catalyst $\left(65.09 \mathrm{mV} \mathrm{dec}^{-1}\right)$, indicating that Mes-C-N-Zn90Co10 has better kinetics during the ORR (Fig. S3). Electrochemical impedance spectroscopy was also obtained at $0.75 \mathrm{~V}$. It can be seen from the Nyquist diagram that the charge transfer resistance $\left(R_{\mathrm{ct}}\right)$ of Mes-C-N-Zn90Co10 is lower than that of other prepared catalysts, confirming that Mes-C-N-Zn90Co10 shows excellent neutral ORR electron transfer performance, as shown in Fig. S4.

To further investigate the application of the porous material in different solution environments, the catalytic performance under alkaline and acidic conditions was tested separately. The ORR performance of the porous material Mes-C-N-Zn90Co10 exhibits an $E_{1 / 2}$ of $0.774 \mathrm{~V}$ and $J$ of $5.554 \mathrm{~mA} \mathrm{~cm}^{-2}$ in $0.1 \mathrm{~mol} \mathrm{~L}^{-1} \mathrm{HClO}_{4}$ solution, showing relatively high values compared with those of Mic-C-N-Zn90Co10 (E $E_{1 / 2}$ of $0.737 \mathrm{~V}$, and $J$ of $\left.4.971 \mathrm{~mA} \mathrm{~cm}^{-2}\right)$ and $\mathrm{Pt} / \mathrm{C}\left(E_{1 / 2}\right.$ of $0.824 \mathrm{~V}$, and $J$ of $5.256 \mathrm{~mA} \mathrm{~cm}^{-2}$ ) (Fig. 5b). Similarly, the ORR test was also performed in a $0.1 \mathrm{~mol} \mathrm{~L}^{-1} \mathrm{KOH}$ solution filled with oxygen. The catalytic performance of Mes-C-N$\mathrm{Zn} 90 \mathrm{Co} 10\left(E_{1 / 2}\right.$ of $0.882 \mathrm{~V}$, and $J$ of $\left.5.743 \mathrm{~mA} \mathrm{~cm}^{-2}\right)$ is superior to that of Mic-C-N-Zn90Co10 $\left(E_{1 / 2}\right.$ of $0.847 \mathrm{~V}$, and $J$ of $\left.5.009 \mathrm{~mA} \mathrm{~cm}^{-2}\right)$ and $\mathrm{Pt} / \mathrm{C}\left(E_{1 / 2}\right.$ of $0.869 \mathrm{~V}$, and $J$ of $5.489 \mathrm{~mA} \mathrm{~cm}^{-2}$ ) (Fig. 5c). Actually, the ORR electrocatalystic activity of the Mes-C-N-Zn90Co10 in different $\mathrm{pH}$ solutions also shows advantages over the other carbon materials reported recently (Tables S4-S6). In addition, methanol resistance tests were carried out. Mes-C-NZn90Co10 shows almost no attenuation after methanol injection in a $0.1 \mathrm{~mol} \mathrm{~L}^{-1} \mathrm{HClO}_{4}$ solution (Fig. 5e) and $0.1 \mathrm{~mol} \mathrm{~L}^{-1} \mathrm{KOH}$ solution (Fig. 5f), while the electrocatalytic performance of the commercial $\mathrm{Pt} / \mathrm{C}$ catalyst decreases rapidly after mixing with methanol. Apparently, Mes-C-N-Zn90Co10 shows better methanol resistance performance than $\mathrm{Pt} / \mathrm{C}$, demonstrating outstanding catalytic selectivity, which is an important indicator for their application in fuel cells.

The long-term durability of Mes-C-N-Zn90Co10 and $\mathrm{Pt} / \mathrm{C}$ was evaluated and compared in oxygen-saturated $0.01 \mathrm{~mol} \mathrm{~L}^{-1} \quad$ PBS electrolyte ( $\mathrm{pH}$ 7.0) (Fig. 5g), $0.1 \mathrm{~mol} \mathrm{~L}^{-1} \mathrm{HClO}_{4}$ (Fig. 5h), and $0.1 \mathrm{~mol} \mathrm{~L}^{-1} \mathrm{KOH}$ 

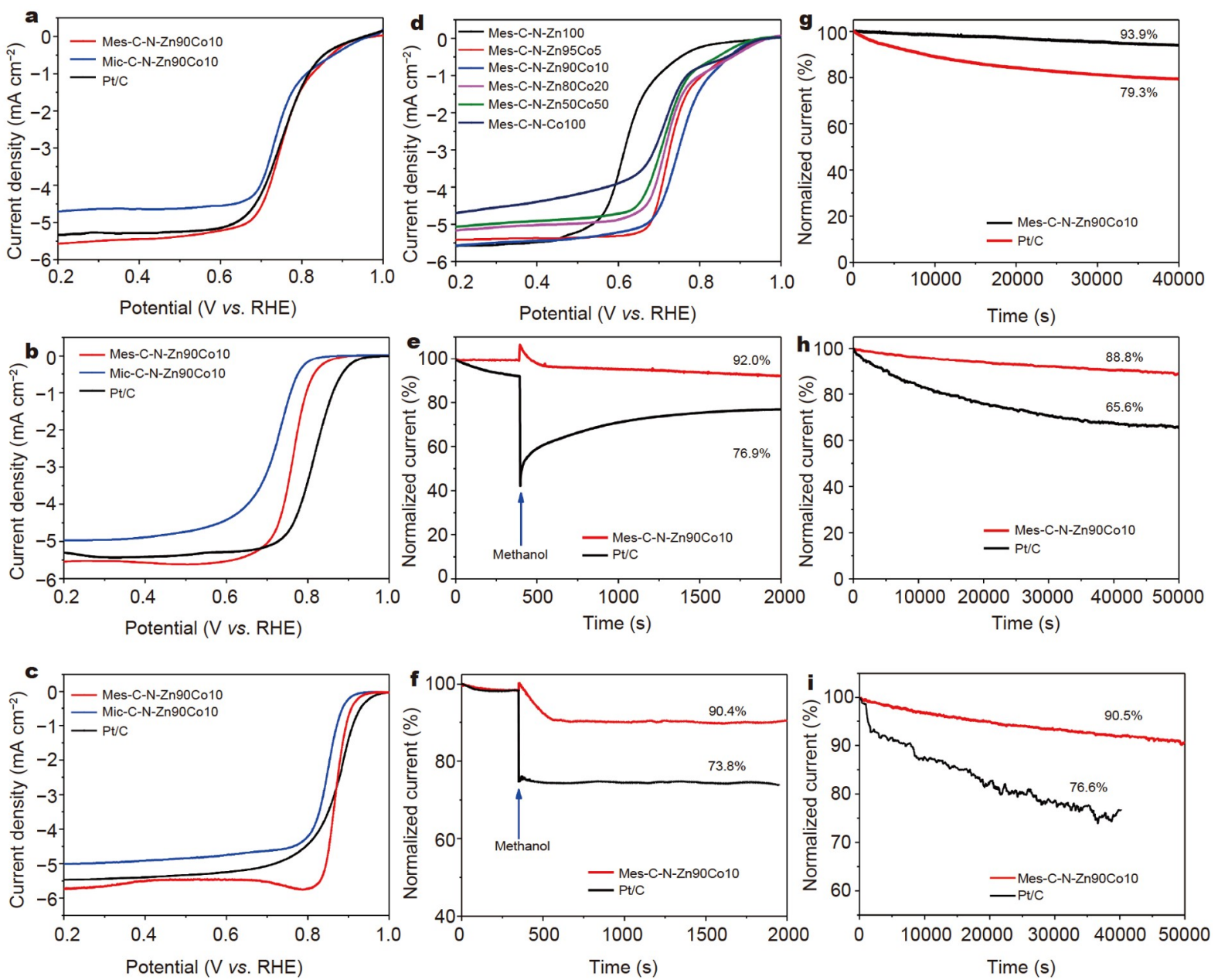

Figure 5 LSV curves of Mes-C-N-Co100, Mic-C-N-Zn90Co10, and commercial Pt/C at $1600 \mathrm{r} \mathrm{min}^{-1}$ in $\mathrm{O}_{2}$-saturated (a) $0.01 \mathrm{~mol} \mathrm{~L}^{-1} \mathrm{PBS}$, (b) $0.1 \mathrm{~mol} \mathrm{~L}^{-1} \mathrm{HClO}_{4}$, and (c) $0.1 \mathrm{~mol} \mathrm{~L}^{-1} \mathrm{KOH}$. (d) LSV curves of Mes-C-N-Zn(100-x)Cox at $1600 \mathrm{r} \mathrm{min}^{-1}$ in $0.01 \mathrm{~mol} \mathrm{~L}{ }^{-1} \mathrm{PBS}$. Methanol resistance curves of Pt/C and Mes-C-N-Zn90Co10 in (e) $0.1 \mathrm{~mol} \mathrm{~L}^{-1} \mathrm{HClO}_{4}$ and (f) $0.1 \mathrm{~mol} \mathrm{~L}^{-1} \mathrm{KOH}$. Durability curves of Pt/C and Mes-C-N-Zn90Co10 in (g) $0.01 \mathrm{~mol} \mathrm{~L}^{-1} \mathrm{PBS}$, (h) $0.1 \mathrm{~mol} \mathrm{~L}^{-1} \mathrm{HClO}_{4}$, and (i) $0.1 \mathrm{~mol} \mathrm{~L}^{-1} \mathrm{KOH}$.

(Fig. 5i). Mes-C-N-Zn90Co10 possesses excellent longterm stability over a broad $\mathrm{pH}$ range. Such high stability may be ascribed to its hierarchical porosity, in which mesopores stabilize the porous carbon structure and expose more pore volume to boost the transport of reactants, intermediates, and products, thereby maintaining a continuous electronic transport pathway for the ORR [49].

Based on the above analysis and discussion, the reason for the excellent catalytic activity of the proposed material is attributed to the following characteristics: (1) Co species can provide more catalytically active sites, while a microporous structure with a large specific surface area can be created by the $\mathrm{Zn}$ species. Through the optimization of the $\mathrm{Co} / \mathrm{Zn}$ ratio, the synergistic effect of these two elements can fully and evenly disperse the Co and N species on the surface of the catalyst, exposing more active sites and promoting the catalytic reaction. (2) The structural characteristics of microporous-mesoporous hierarchical pores create a short path for oxygen diffusion and ion mass transfer, which can accelerate the diffusion reaction at the gas-liquid-solid interface. (3) Highly graphitized pyridinic-N, graphitic- $\mathrm{N}$, and pyrrolic- $\mathrm{N}$ with excellent electrical conductivity can promote electron transfer and accelerate the conversion of chemical energy into electrical energy.

Since the prepared Mes-C-N-Zn90Co10 shows excellent ORR electrocatalytic performance, it was applied as the catalyst in an MFC to further explore the feasibility of its industrial application. Therefore, carbon paper 

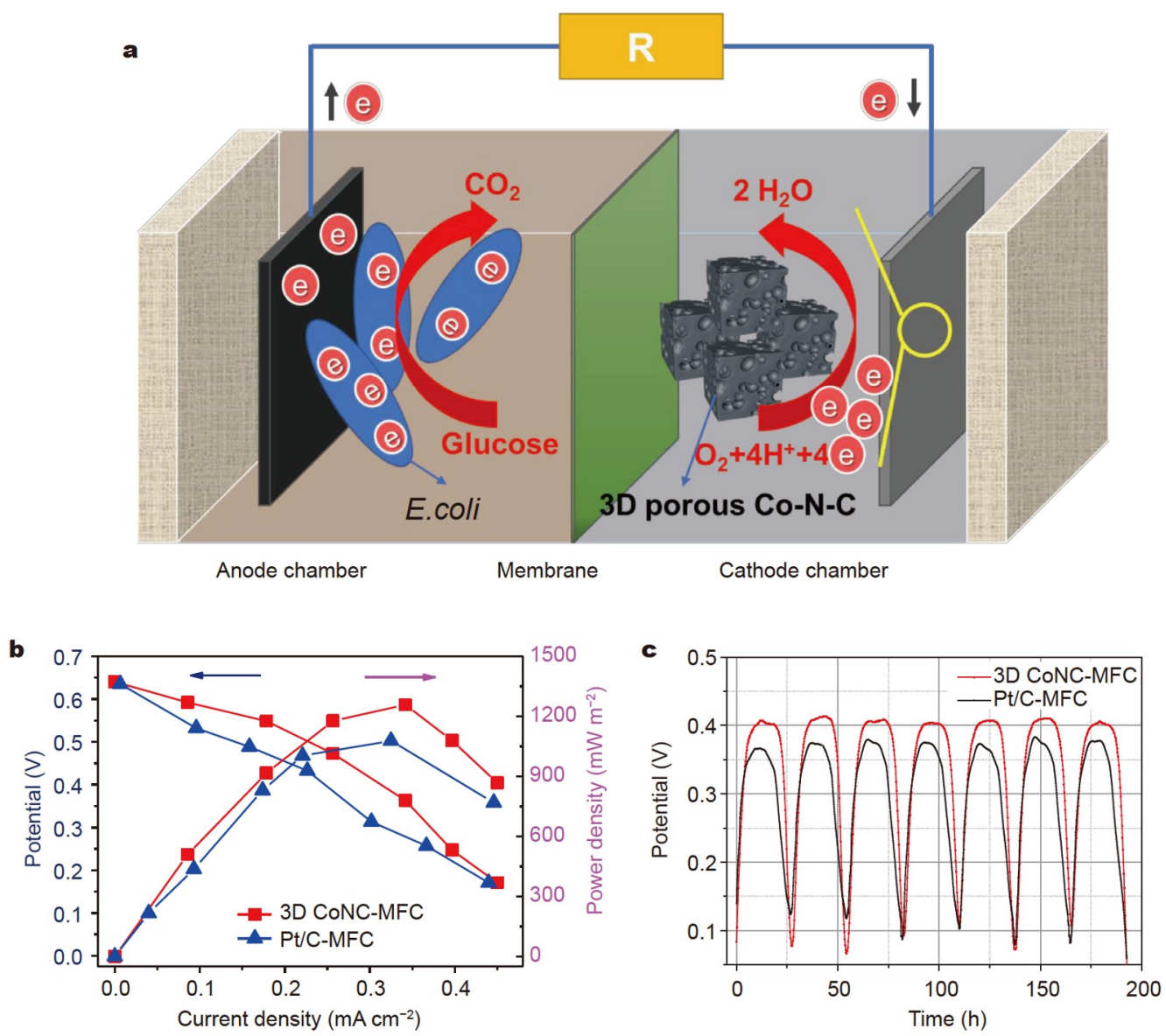

Figure 6 (a) Diagram showing the working principle of MFCs. (b) Polarization curves and discharge power densities of the 3D CoNC-MFC and Pt/ $\mathrm{C}-\mathrm{MFC}$ devices. (c) Voltage trend recorded for $192 \mathrm{~h}$ for the MFCs equipped with Mes-C-N-Zn90Co10 and Pt/C. The voltage was recorded across a $1000-\Omega$ resistor.

supported by Mes-C-N-Zn90Co10 (denoted as 3D CoNC-MFC) or Pt/C (denoted as 3D CoNC-MFC) was used as the cathode in a single-chamber MFC device and studied to ascertain the probability of using Mes-C-N$\mathrm{Zn} 90 \mathrm{Co} 10$ as a substitute for $\mathrm{Pt} / \mathrm{C}$ as the cathode catalyst (Fig. 6). The anode chamber contained a certain amount of $E$. coli to generate electrons by decomposing a glucose solution, while the cathode chamber was filled with air and the catalyst promoting the ORR (Fig. 6a). The maximum discharge watt density of the 3D CoNC-MFC is $1257 \mathrm{~mW} \mathrm{~m}^{-2}$, which is $17 \%$ higher than that of the $\mathrm{Pt} / \mathrm{C}-\mathrm{MFC}\left(1078 \mathrm{~mW} \mathrm{~m}^{-2}\right.$ ) (Fig. 6b). This result is consistent with the previous LSV electrochemical performance results, indicating the power generation potential of 3D Mes-C-N-Zn90Co10 as an electrocatalyst. More importantly, the 3D CoNC-MFC shows outstanding durability with the regular feeding of nutrients. Fig. $6 c$ shows that the voltage gradually decreases with the con- sumption of nutrients in the MFC. After adding fresh anodic nutrient solution, the voltage can quickly recover to the initial value. During periodic feeding operation for $192 \mathrm{~h}$, the voltage of the 3D CoNC-MFC device has no obvious attenuation. The experimental data indicate that compared with $\mathrm{Pt} / \mathrm{C}$, Mes-C-N-Zn90Co10 as a cathode catalyst can generate a competitive voltage, showing it has potential application prospects in MFCs that stably operate for a long time. This potential is mainly because micropores contribute to exposing the active areas, and mesopores help $\mathrm{O}_{2}$ adequately diffuse to the active sites [50-53]. The hierarchically porous framework formed by the combination of micropores and mesopores contributes to enhancing the ORR catalytic activity and MFC-cathode power output performance.

\section{CONCLUSIONS}

In summary, a bi-MOF-derived carbon with a novel 3D 
hierarchically porous nanocubic Swiss cheese-like structure was successfully synthesized through a simple, novel, and green strategy in a water system. The combination of micropores formed by the high-temperature evaporation of $\mathrm{Zn}$ and mesopores formed by the nanocasting of a $\mathrm{SiO}_{2}$ template promoted the generation of hierarchical pores in the catalyst. Due to its good 3D layered porosity, large specific surface area, and good distribution of the 3D Co$\mathrm{N}-\mathrm{C}$ active components, the prepared 3D hierarchically porous catalyst exhibited excellent ORR catalysis in neutral environments and had excellent resistance to methanol, showing significant durability. In addition, we reported Mes-C-N-Zn90Co10 as an air cathode catalyst for MFC devices. Compared with the Pt/C-MFC device (power density of $1078 \mathrm{~mW} \mathrm{~m}^{-2}$ ), the 3D CoNC-MFC device showed a higher power density $\left(1257 \mathrm{~mW} \mathrm{~m}^{-2}\right)$ and had excellent durability. In short, the 3D porous Co$\mathrm{N}-\mathrm{C}$ material with a unique hierarchical pore structure provided a large number of $\mathrm{O}_{2}$ transport channels and exposed abundant catalytically active sites. The results of this study are not only essential for the industrial production of non-Pt-based ORR catalysts for use in MFC cathodes but also expand an original perspective to invent novel nanomaterials for alternative new energy materials, such as batteries, supercapacitors, and catalysts.

Received 4 March 2021; accepted 7 May 2021; published online 5 July 2021

1 Li WW, Yu HQ, He Z. Towards sustainable wastewater treatment by using microbial fuel cells-centered technologies. Energy Environ Sci, 2014, 7: 911-924

2 Logan BE. Exoelectrogenic bacteria that power microbial fuel cells. Nat Rev Microbiol, 2009, 7: 375-381

3 Santoro C, Arbizzani C, Erable B, et al. Microbial fuel cells: From fundamentals to applications. A review. J Power Sources, 2017, 356: $225-244$

4 Sun M, Zhai LF, Li WW, et al. Harvest and utilization of chemical energy in wastes by microbial fuel cells. Chem Soc Rev, 2016, 45: 2847-2870

5 Pant D, Van Bogaert G, Diels L, et al. A review of the substrates used in microbial fuel cells (MFCs) for sustainable energy production. Bioresource Tech, 2010, 101: 1533-1543

6 Wang H, Park JD, Ren ZJ. Practical energy harvesting for microbial fuel cells: A review. Environ Sci Technol, 2015, 49: 3267-3277

7 Zhao F, Slade RCT, Varcoe JR. Techniques for the study and development of microbial fuel cells: An electrochemical perspective. Chem Soc Rev, 2009, 38: 1926-1939

8 Martinez U, Komini Babu S, Holby EF, et al. Progress in the development of Fe-based PGM-free electrocatalysts for the oxygen reduction reaction. Adv Mater, 2019, 31: 1806545

9 Wang Q, Astruc D. State of the art and prospects in metal-organic framework (MOF)-based and MOF-derived nanocatalysis. Chem Rev, 2019, 120: 1438-1511

10 Santoro C, Serov A, Gokhale R, et al. A family of Fe-N-C oxygen reduction electrocatalysts for microbial fuel cell (MFC) application: Relationships between surface chemistry and performances. Appl Catal B-Environ, 2017, 205: 24-33

11 You S, Gong X, Wang W, et al. Enhanced cathodic oxygen reduction and power production of microbial fuel cell based on noble-metal-free electrocatalyst derived from metal-organic frameworks. Adv Energy Mater, 2016, 6: 1501497

12 Cai S, Meng Z, Tang H, et al. 3D Co-N-doped hollow carbon spheres as excellent bifunctional electrocatalysts for oxygen reduction reaction and oxygen evolution reaction. Appl Catal BEnviron, 2017, 217: 477-484

13 Cai S, Wang R, Yourey WM, et al. An efficient bifunctional electrocatalyst derived from layer-by-layer self-assembly of a threedimensional porous Co-N-C@graphene. Sci Bull, 2019, 64: 968975

14 Meng Z, Cai S, Wang R, et al. Bimetallic-organic framework-derived hierarchically porous Co-Zn-N-C as efficient catalyst for acidic oxygen reduction reaction. Appl Catal B-Environ, 2019, 244: $120-127$

15 Tang H, Cai S, Xie S, et al. Metal-organic-framework-derived dual metal- and nitrogen-doped carbon as efficient and robust oxygen reduction reaction catalysts for microbial fuel cells. Adv Sci, 2016, 3: 1500265

16 Tang H, Zeng Y, Liu D, et al. Dual-doped mesoporous carbon synthesized by a novel nanocasting method with superior catalytic activity for oxygen reduction. Nano Energy, 2016, 26: 131-138

17 Tang $\mathrm{H}$, Zeng $\mathrm{Y}$, Zeng $\mathrm{Y}$, et al. Iron-embedded nitrogen doped carbon frameworks as robust catalyst for oxygen reduction reaction in microbial fuel cells. Appl Catal B-Environ, 2017, 202: 550556

18 Wang R, Cao J, Cai S, et al. MOF@cellulose derived Co-N-C nanowire network as an advanced reversible oxygen electrocatalyst for rechargeable zinc-air batteries. ACS Appl Energy Mater, 2018, 1: $1060-1068$

19 Mamtani K, Jain D, Zemlyanov D, et al. Probing the oxygen reduction reaction active sites over nitrogen-doped carbon nanostructures $\left(\mathrm{CN}_{x}\right)$ in acidic media using phosphate anion. ACS Catal, 2016, 6: 7249-7259

20 Yin $\mathrm{P}$, Yao T, Wu Y, et al. Single cobalt atoms with precise Ncoordination as superior oxygen reduction reaction catalysts. Angew Chem, 2016, 128: 10958-10963

21 Xia BY, Yan Y, Li N, et al. A metal-organic framework-derived bifunctional oxygen electrocatalyst. Nat Energy, 2016, 1: 15006

22 Dang S, Zhu QL, Xu Q. Nanomaterials derived from metal-organic frameworks. Nat Rev Mater, 2018, 3: 17075

23 Lu XF, Xia BY, Zang SQ, et al. Metal-organic frameworks based electrocatalysts for the oxygen reduction reaction. Angew Chem Int Ed, 2020, 59: 4634-4650

24 Shui J, Chen C, Grabstanowicz L, et al. Highly efficient nonprecious metal catalyst prepared with metal-organic framework in a continuous carbon nanofibrous network. Proc Natl Acad Sci USA, 2015, 112: 10629-10634

25 Shang L, Yu H, Huang X, et al. Well-dispersed ZIF-derived Co,NCo-doped carbon nanoframes through mesoporous-silica-protected calcination as efficient oxygen reduction electrocatalysts. Adv Mater, 2016, 28: 1668-1674

26 Liang HW, Zhuang X, Brüller S, et al. Hierarchically porous carbons with optimized nitrogen doping as highly active electrocatalysts for oxygen reduction. Nat Commun, 2014, 5: 4973

27 Lai $\mathrm{Q}$, Zhao $\mathrm{Y}$, Liang $\mathrm{Y}$, et al. In situ confinement pyrolysis 
transformation of ZIF-8 to nitrogen-enriched meso-microporous carbon frameworks for oxygen reduction. Adv Funct Mater, 2016, 26: $8334-8344$

28 Li Z, Shao M, Zhou L, et al. Directed growth of metal-organic frameworks and their derived carbon-based network for efficient electrocatalytic oxygen reduction. Adv Mater, 2016, 28: 2337-2344 Li Y, Fu ZY, Su BL. Hierarchically structured porous materials for energy conversion and storage. Adv Funct Mater, 2012, 22: 46344667

30 Li F, Ding XB, Cao QC, et al. A ZIF-derived hierarchically porous Fe-Zn-N-C catalyst synthesized via a two-stage pyrolysis for the highly efficient oxygen reduction reaction in both acidic and alkaline media. Chem Commun, 2019, 55: 13979-13982

31 Ren Q, Wang H, Lu XF, et al. Recent progress on MOF-derived heteroatom-doped carbon-based electrocatalysts for oxygen reduction reaction. Adv Sci, 2018, 5: 1700515

32 Ye L, Chai G, Wen Z. Zn-MOF-74 derived N-doped mesoporous carbon as $\mathrm{pH}$-universal electrocatalyst for oxygen reduction reaction. Adv Funct Mater, 2017, 27: 1606190

33 Yang L, Zeng X, Wang W, et al. Recent progress in MOF-derived, heteroatom-doped porous carbons as highly efficient electrocatalysts for oxygen reduction reaction in fuel cells. Adv Funct Mater, 2018, 28: 1704537

34 Zhou H, Yang T, Kou Z, et al. Negative pressure pyrolysis induced highly accessible single sites dispersed on 3D graphene frameworks for enhanced oxygen reduction. Angew Chem, 2020, 132: 2064520649

35 Zhu M, Zhao C, Liu X, et al. Single atomic cerium sites with a high coordination number for efficient oxygen reduction in protonexchange membrane fuel cells. ACS Catal, 2021, 11: 3923-3929

36 Zhou S, Lin M, Zhuang Z, et al. Biosynthetic graphene enhanced extracellular electron transfer for high performance anode in microbial fuel cell. Chemosphere, 2019, 232: 396-402

37 Qiao Y, Bao SJ, Li CM, et al. Nanostructured polyaniline/titanium dioxide composite anode for microbial fuel cells. ACS Nano, 2008, 2: 113-119

$38 \mathrm{Hu} \mathrm{H}$, Guan BY, Lou XWD. Construction of complex CoS hollow structures with enhanced electrochemical properties for hybrid supercapacitors. Chem, 2016, 1: 102-113

39 You B, Jiang N, Sheng M, et al. Bimetal-organic framework selfadjusted synthesis of support-free nonprecious electrocatalysts for efficient oxygen reduction. ACS Catal, 2015, 5: 7068-7076

40 Pan Y, Heryadi D, Zhou F, et al. Tuning the crystal morphology and size of zeolitic imidazolate framework-8 in aqueous solution by surfactants. CrystEngComm, 2011, 13: 6937-6940

41 Yao J, He M, Wang H. Strategies for controlling crystal structure and reducing usage of organic ligand and solvents in the synthesis of zeolitic imidazolate frameworks. CrystEngComm, 2015, 17: 4970-4976

42 Hou X, Zhang Y, Dong Q, et al. Metal organic framework derived core-shell structured $\mathrm{Co}_{9} \mathrm{~S}_{8} @ \mathrm{~N}-\mathrm{C} @ \mathrm{MoS}_{2}$ nanocubes for supercapacitor. ACS Appl Energy Mater, 2018, 1: 3513-3520

43 Liu H, Guan J, Yang S, et al. Metal-organic framework-derived $\mathrm{Co}_{2} \mathrm{P}$ nanoparticle/multi-doped porous carbon as a trifunctional electrocatalyst. Adv Mater, 2020, 32: 2003649

44 Wang J, Huang Z, Liu W, et al. Design of N-coordinated dualmetal sites: A stable and active Pt-free catalyst for acidic oxygen reduction reaction. J Am Chem Soc, 2017, 139: 17281-17284

45 Mi JL, Liang JH, Yang LP, et al. Effect of Zn on size control and oxygen reduction reaction activity of Co nanoparticles supported on N-doped carbon nanotubes. Chem Mater, 2019, 31: 8864-8874 46 Chen YZ, Wang C, Wu ZY, et al. From bimetallic metal-organic framework to porous carbon: High surface area and multicomponent active dopants for excellent electrocatalysis. Adv Mater, 2015, 27: 5010-5016

47 Li JS, Li SL, Tang YJ, et al. Nitrogen-doped Fe/Fe ${ }_{3} \mathrm{C} @$ graphitic layer/carbon nanotube hybrids derived from MOFs: Efficient bifunctional electrocatalysts for ORR and OER. Chem Commun, 2015, 51: 2710-2713

48 Amiinu IS, Liu X, Pu Z, et al. From 3D ZIF nanocrystals to Co-N $\mathrm{N}_{x}$ $\mathrm{C}$ nanorod array electrocatalysts for ORR, OER, and $\mathrm{Zn}$-air batteries. Adv Funct Mater, 2018, 28: 1704638

49 Deng Y, Tian X, Chi B, et al. Hierarchically open-porous carbon networks enriched with exclusive $\mathrm{Fe}-\mathrm{N}_{x}$ active sites as efficient oxygen reduction catalysts towards acidic $\mathrm{H}_{2}-\mathrm{O}_{2}$ PEM fuel cell and alkaline Zn-air battery. Chem Eng J, 2020, 390: 124479

50 Wang J, Lu H, Hong Q, et al. Porous N,S-codoped carbon architectures with bimetallic sulphide nanoparticles encapsulated in graphitic layers: Highly active and robust electrocatalysts for the oxygen reduction reaction in Al-air batteries. Chem Eng J, 2017, 330: $1342-1350$

$51 \mathrm{Li} \mathrm{G}, \mathrm{Mu} \mathrm{Y}$, Huang Z, et al. Poly-active centric $\mathrm{Co}_{3} \mathrm{O}_{4}-\mathrm{CeO}_{2} / \mathrm{Co}-\mathrm{N}$ $\mathrm{C}$ composites as superior oxygen reduction catalysts for $\mathrm{Zn}$-air batteries. Sci China Mater, 2021, 64: 73-84

52 Chen Y, Gao R, Ji S, et al. Atomic-level modulation of electronic density at cobalt single-atom sites derived from metal-organic frameworks: Enhanced oxygen reduction performance. Angew Chem Int Ed, 2021, 60: 3212-3221

$53 \mathrm{Hu} \mathrm{Y}$, Zhu M, Luo X, et al. Coplanar Pt/C nanomeshes with ultrastable oxygen reduction performance in fuel cells. Angew Chem Int Ed, 2021, 60: 6533-6538

Acknowledgements This work was supported by the National Natural Science Foundation of China (51976143), the National Key Research and Development Program of China (2018YFA0702001), and Foshan Xianhu Laboratory of the Advanced Energy Science and Technology Guangdong Laboratory (XHD2020-002).

Author contributions Tang $\mathrm{H}$ conceived the idea of the subject and supervised the progress of the research. Chen $\mathrm{N}$ performed the experiments with support from Meng Z, Wang R, Cai S, and Guo W. Chen N wrote the manuscript, and Tang $\mathrm{H}$ revised the manuscript. All authors contributed to the general discussion.

Conflict of interest The authors declare that they have no conflict of interest.

Supplementary information Supporting data are available in the online version of the paper. 


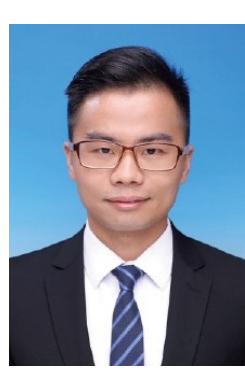

Neng Chen obtained his bachelor's degree from Guangdong University of Petroleum and Chemical Technology in 2015. He obtained a master's degree from China University of Petroleum, Beijing in 2018. And he has been a scientific research assistant at the State Key Laboratory of Advanced Technology for Materials Synthesis and Processing at Wuhan University of Technology until now. His research interests focus on electrocatalysts, fuel cells and metal-air batteries.

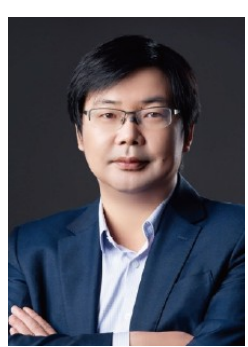

Haolin Tang earned his $\mathrm{PhD}$ degree in materials science from Wuhan University of Technology in 2007. Then he worked as a research fellow at Nanyang Technological University for one year, and in 2011 he was appointed as a full professor of the State Key Laboratory of Advanced Technology for Materials Synthesis and Processing at Wuhan University of Technology. His research interests include fuel cells, electrochemistry of nanomaterials, and self-assembly of nanocomposites.

\section{双金属有机骨架衍生的3D等级孔结构纳米立方碳} 在微生物燃料电池中的应用

陈能 ${ }^{1,2}$, 孟子寒 ${ }^{1,2}$, 王锐 ${ }^{2}$ 蔡世昌 ${ }^{2}$, 郭伟斌 ${ }^{2}$, 唐浩林 ${ }^{1,2^{*}}$

摘要 多级孔结构的非贵金属高性能催化剂在微生物燃料电池 $(M F C)$ 氧化还原反应 (ORR)中的应用, 是近年来备受关注的话题. 在此, 我们报道了一种在双金属MOFs中衍生出的奶酪状三维多级 孔结构立方碳材料. 该材料通过十六烷基三甲基溴化铵(CTAB)作 为结构导向剂来控制形成纳米立方骨架, 同时采用二氧化硅微球 作模板形成介孔结构, 并通过调节双金属MOFs的Co/Zn 比例来优 化材料的物理化学性质, 从而提升催化剂的ORR电化学性能. 经过 优化的 $3 \mathrm{D} \mathrm{Co}-\mathrm{N}-\mathrm{C}$ 在中性 $0.01 \mathrm{~mol} \mathrm{~L}^{-1}$ 磷酸盐缓冲液电解质中具有 优异的ORR催化性能(相对于可逆氢电极的半波电势高达 $0.754 \mathrm{~V}$, 扩散极限电流密度为 $5.576 \mathrm{~mA} \mathrm{~cm}^{-2}$ ), 可与商用 $20 \mathrm{wt} \% \mathrm{Pt} / \mathrm{C}$ 的催化 性能相匹敌. 同时, 这种催化剂与 $\mathrm{Pt} / \mathrm{C}$ 相比具有更长的寿命. 将三维 多级孔材料(3D CoNC-MFC)作为MFC装置中阴极的催化剂, 测试 了其功率密度和长期耐用性, 结果表明 $3 \mathrm{D}$ CoNC-MFC能到达 $1257 \mathrm{~mW} \mathrm{~m}^{-2}$ 的高功率密度, 并且在 $192 \mathrm{~h}$ 的常规加料操作下仍然 保持较高的电压, 性能远高于Pt/C-MFC. 